\title{
On the variability of the seasonal scale oscillations over Cachoeira Paulista $\left(22.7^{\circ} \mathrm{S}, 45^{\circ} \mathrm{W}\right)$, Brazil
}

\author{
Amitava Guharay*, Paulo Prado Batista and Barclay Robert Clemesha
}

\begin{abstract}
The characteristics of long period atmospheric oscillations are studied using long-term meteor radar wind observations over a low-latitude Brazilian station, Cachoeira Paulista $\left(22.7^{\circ} \mathrm{S}, 45^{\circ} \mathrm{W}\right)$. The semiannual oscillation (SAO) amplitude decreases gradually with altitude in the mesopause region, while the annual oscillation (AO) amplitude exhibits a minimum at mid-mesopause with significant interannual variability. The quasi-biennial oscillation (QBO) obtained by removing the $\mathrm{SAO}$ and $\mathrm{AO}$ from the zonal wind exhibits an out-of-phase relationship at lower mesopause heights (approximately $81 \mathrm{~km}$ ) and mid-stratosphere (approximately $10 \mathrm{hPa}$ ). There is an evident signature of modulation of the mesospheric SAO (MSAO) and mesospheric $\mathrm{AO}(\mathrm{MAO})$ by the QBO. The diurnal tide is surmised to contribute significantly to drive the easterly phase of these oscillations, especially MSAO and MAO through depositing westward momentum to the background wind. The westerly phase of the MSAO is believed to support the growth of the quasi-2-day wave (QTDW) by wave filtering. The QTDW is found to be strong during the easterly phase of the MAO indicating a possible existence of the barotropic/baroclinic instability during summer and a possible role of the QTDW towards westward forcing of the background wind.
\end{abstract}

Keywords: Seasonal oscillations; Diurnal tide; Quasi-2-day wave

\section{Background}

The low-latitude middle atmosphere supports a number of waves of various scales which control the dynamical condition of this region to a great extent. The interaction of these waves with the mean wind gives rise to a number of long period seasonal scale oscillations, e.g., the semiannual oscillation (SAO), annual oscillation (AO), and quasi-biennial oscillation (QBO) (Delisi and Dunkerton 1988; Burrage et al. 1996; Sassi and Garcia 1994; Guharay et al. 2009; $\mathrm{Li}$ et al. 2012). The SAO and QBO are driven by breaking and dissipation of gravity waves, Rossby waves, and Kelvin waves (Dunkerton 1982; Burrage et al. 1996; Sato and Dunkerton 1997; Li et al. 2012). The SAO is prominent in the zonal wind and temperature, and it is found that the stratospheric SAO (SSAO) maximizes its amplitude near the stratopause (Reed 1966) and the mesospheric SAO (MSAO) exhibits its peak in the upper mesosphere with opposite phase (Garcia et al. 1997). On the other hand, the MAO is generally strong in the meridional wind and temperature (Sridharan

\footnotetext{
* Correspondence: guharay@laser.inpe.br

National Institute for Space Research, INPE, São José dos Campos, SP 12227-010, Brazil
}

et al. 2007; Guharay et al. 2009). The MAO is driven by seasonal reversal of the mean meridional flow in the upper mesosphere and mesopause region due to breaking of small scale gravity waves and planetary waves (Holton and Wehrbein 1980; Holton 1983). Existence of the MAO in the meridional wind is characterized by cross-equatorial flow from summer to winter hemisphere signifying an outof-phase relationship between two hemispheres (Burrage et al. 1996).

In general, the $\mathrm{SAO}$ in the middle atmosphere is strongest at equatorial latitudes and diminishes at subtropical locations and is then taken over by the $\mathrm{AO}$ at middle and high latitudes. The stratospheric QBO (SQBO), a distinctive feature of the zonal wind, maximizes its amplitude near mid-stratosphere, and the mesospheric QBO (MQBO) reaches its maximum in the mesopause region (Burrage et al. 1996; Baldwin et al. 2001). It is believed that gravity waves that pass through the SQBO break/dissipate in the mesosphere driving the equatorial MQBO (Baldwin et al. 2001). The easterly phase of the MSAO is observed to be strong during the westerly phase of the SQBO and weak during easterly phase of the SQBO in the tropics suggesting a modulation of the SAO by the

\section{Springer}


QBO (Burrage et al. 1996; Garcia et al. 1997). In contrast, $\mathrm{Li}$ et al. (2012) reported strong easterly MSAO during the easterly phase of the SQBO and weak easterly MSAO during the westerly phase of the SQBO in the subtropical region. In general, the SSAO and MSAO exhibit an antiphase relationship with westerly (easterly) winds during equinoxes and easterly (westerly) during solstices.

Dunkerton (1982) explained that due to selective filtering by the stratopause, SAO gravity waves and Kelvin waves which reach the mesosphere cause a mesopause SAO of opposite phase. Garcia et al. (1997) described QBO modulation of the SSAO due to filtering of the gravity waves by the QBO. They concluded that seasonal variation of sources and propagation of small scale gravity waves are responsible for such phenomena. Using meteor radar observations over a subtropical station, Li et al. (2012) inferred a possibility of contributions to QBO modulation of the MSAO from gravity wave drag and the Eliassen-Palm flux due to the quasi-2-day wave (QTDW). Delisi and Dunkerton (1988) first reported the asymmetry in the peaks of the SSAO cycle. They noted that the first cycle starting in the northern hemisphere winter is stronger than the second cycle starting in the summer. Such asymmetry is ascribed to the stronger dynamical forcing in winter than in summer. Using the data from ground-based MF radar and High Resolution Doppler Imager (HRDI) onboard the Upper Atmosphere Research Satellite (UARS), Garcia et al. (1997) also reported seasonal asymmetry in the MSAO which is most prominent in the 80 - to $85-\mathrm{km}$ altitude region. Therefore, all of these earlier studies indicate a significant control of the stratospheric oscillations over mesospheric oscillations.

The basic characteristics of these long period oscillations and their effect on the middle atmosphere are known to some extent. Although a handful of investigations with the help of modeling and observational approaches have been carried out over the last couple of decades for various stations around the globe, the causative mechanisms for their temporal variability are not completely known so far. Also, literatures related to long period oscillations from southern hemispheric stations with long-term data are scarce. In our present paper, we study the characteristic behaviors of SAO, AO, and QBO in the mesopause and their relation with stratospheric oscillations using meteor radar zonal wind and reanalysis data from a Brazilian low-latitude site. The relationship of these oscillations with the diurnal tide and QTDW is also looked into.

\section{Methods}

\section{Database and analyses}

The horizontal wind data utilized in the present study are obtained from a SKiYMET type meteor radar installed at Cachoeira Paulista $\left(22.7^{\circ} \mathrm{S}, 45^{\circ} \mathrm{W}\right)$. The radar operates at
35.24 $\mathrm{MHz}$ with a pulse width of $13 \mu \mathrm{s}$, pulse repetition frequency of $2 \mathrm{kHz}$ and peak power of $12 \mathrm{~kW}$. For transmission it utilizes one three-element Yagi antenna and to receive the backscattered signal from the meteor trails, five phase-coherent two-element Yagi antennas fixed along two orthogonal baselines with a common antenna at the center are used. The radar can detect approximately 5,000 echoes per day which are utilized to derive range, angular position, and horizontal wind components. Details of the derivation algorithm for estimating the atmospheric parameters can be found in Hocking et al. (2001).

For the present work, we use horizontal wind data with vertical resolution at $3 \mathrm{~km}$ in the range 81 to $99 \mathrm{~km}$ and temporal resolution of $1 \mathrm{~h}$ for the period of March 1999 to November 2008. To eliminate tidal aliasing, dominant tides $(24,12$, and $8 \mathrm{~h})$ are removed from the raw data by applying a least square sinusoidal fit with a 1-day window and 1-day progressive shift. We consider only those days where the window contains at least $18 \mathrm{~h}$ (three fourths window width) data coverage. The daily mean data are calculated with the tide-removed data. The daily mean data has undergone a low-pass filter cutoff of 90 days to get rid of the effect of intra-seasonal oscillations.

The monthly mean data obtained from the filtered daily means are utilized to look into the features of the MSAO, MAO, and MQBO. In the present work, we use the zonal wind data since all the three oscillations are very prominent (the meridional wind only reveals the $\mathrm{AO})$. To extract the QBO, we have deseasonalized the data by removing the climatological mean, SAO, and AO components. The SAO and AO amplitude and phase are determined by least square fit with periods of 6 and 12 months, respectively. Therefore, the QBO temporal variation can be expressed as $Y(t)_{\mathrm{QBO}}=Y(t)-Y(t)_{\mathrm{rem}}$, where $Y(t)$ is the monthly mean wind and $Y(t)_{\text {rem }}$ is obtained by least square fit

$$
Y(t)_{\mathrm{rem}}=Y_{0}+\sum_{n=1,2} A_{n} \sin \left[\frac{2 \pi n}{12}\left(t-\phi_{n}\right)\right]
$$

where $Y_{0}$ is the climatological mean over whole observational span, $A$ is the amplitude, and $\phi$ is the phase of the $\mathrm{AO}(n=1)$ and SAO $(n=2)$.

To determine the relationship of the diurnal tide with the long period oscillations, the tidal amplitude is estimated. The raw wind data is subjected to a high-pass filter cutoff at $30 \mathrm{~h}$ to eliminate higher periods. Subsequently, the data is subjected to a least square sinusoidal fit of 24-h period with a 2-day window and 1-day progressive shift to estimate the daily tidal amplitude. Only those days are considered when the window contains at least $36 \mathrm{~h}$ (three fourths window width) data coverage. The daily amplitudes are averaged for a calendar month to obtain the monthly mean values. 
In order to illustrate the relationship of the QTDW with these oscillations, the kinetic energy of the QTDW is calculated with hourly data. First, the dominant tides (24, 12, and $8 \mathrm{~h}$ ) are removed from the raw data as described before. Subsequently, the tide-removed data is subjected to a band-pass filter with cutoffs of 40 and $60 \mathrm{~h}$ to consider only the QTDW period range. Then the variance is calculated with the filtered data with a window of 4 days and 1 day progressive shift in the zonal and meridional winds to estimate the kinetic energy per unit mass which is obtained as $\left(\overline{u^{\prime 2}}+\overline{v^{\prime 2}}\right) / 2$, where $u$ and $v$ represent the zonal and meridional winds, respectively. The monthly means are estimated from the daily energies.

For obtaining the stratospheric oscillation characteristics, we use the ERA-Interim reanalysis dataset provided by the European Centre for Medium-Range Weather Forecasts (ECMWF). For the present purpose, we use the daily mean of zonal mean zonal wind data nearest to our observing station latitude $\left(22.75^{\circ} \mathrm{S}\right)$ at $10 \mathrm{hPa}$ pressure level (approximately $31 \mathrm{~km}$ ) for the temporal span from January 1999 to December 2008. The oscillation components are derived/ removed in the same way as described in the case of the meteor radar.

\section{Results}

Interannual and seasonal behavior of the SAO and AO In order to find long-term variability over Cachoeira Paulista, the monthly mean radar zonal wind in the mesopause over the observation period is shown in Figure 1. A long data gap, prominent during late 2006 and 2007, is due to technical problems. A westerly wind is dominant during the observational span especially at lower altitudes. A strong westerly wind is prominent during winter (May to August) of all the years at the lowest altitude ( 81 to $84 \mathrm{~km}$ ) indicating a possible presence of the AO. Also, a strong easterly wind is observed near the equinoxes (February to April and September to October) signifying a probable SAO. The strongest easterly and westerly winds are found to exist in 2002 at $81-$ to $84-\mathrm{km}$ altitude. At the highest altitude (96 to $99 \mathrm{~km}$ ), a strong easterly wind is conspicuous during winter although relatively weak during 1999, 2004, and 2005 implying an interannual variability.

Seasonal variability is looked into by computing the composite monthly mean zonal wind over a year span derived from all the years under consideration and plotted in Figure 2. The plot shows significant variability of the zonal wind over various times of the year as well as with altitude. The strongest westerly wind (maximum of approximately $49 \mathrm{~m} / \mathrm{s}$ ) is found during June to July near 81 to $84 \mathrm{~km}$. A dominant easterly wind is also observed during March and October at 81 to $84 \mathrm{~km}$. At higher altitudes (96 to $99 \mathrm{~km}$ ), the strong easterly wind is prominent during winter and spring (May to September) and the westerly wind is significant during summer (November to March). During November to December, the westerly wind is dominating over the entire altitude range. The westerly wind exhibits quite high values near 93 to $96 \mathrm{~km}$ during December as compared to the rest of the year. Therefore, the observed results indicate the possibility of a dominant MAO and MSAO at lower mesopause heights and an MAO at higher heights.

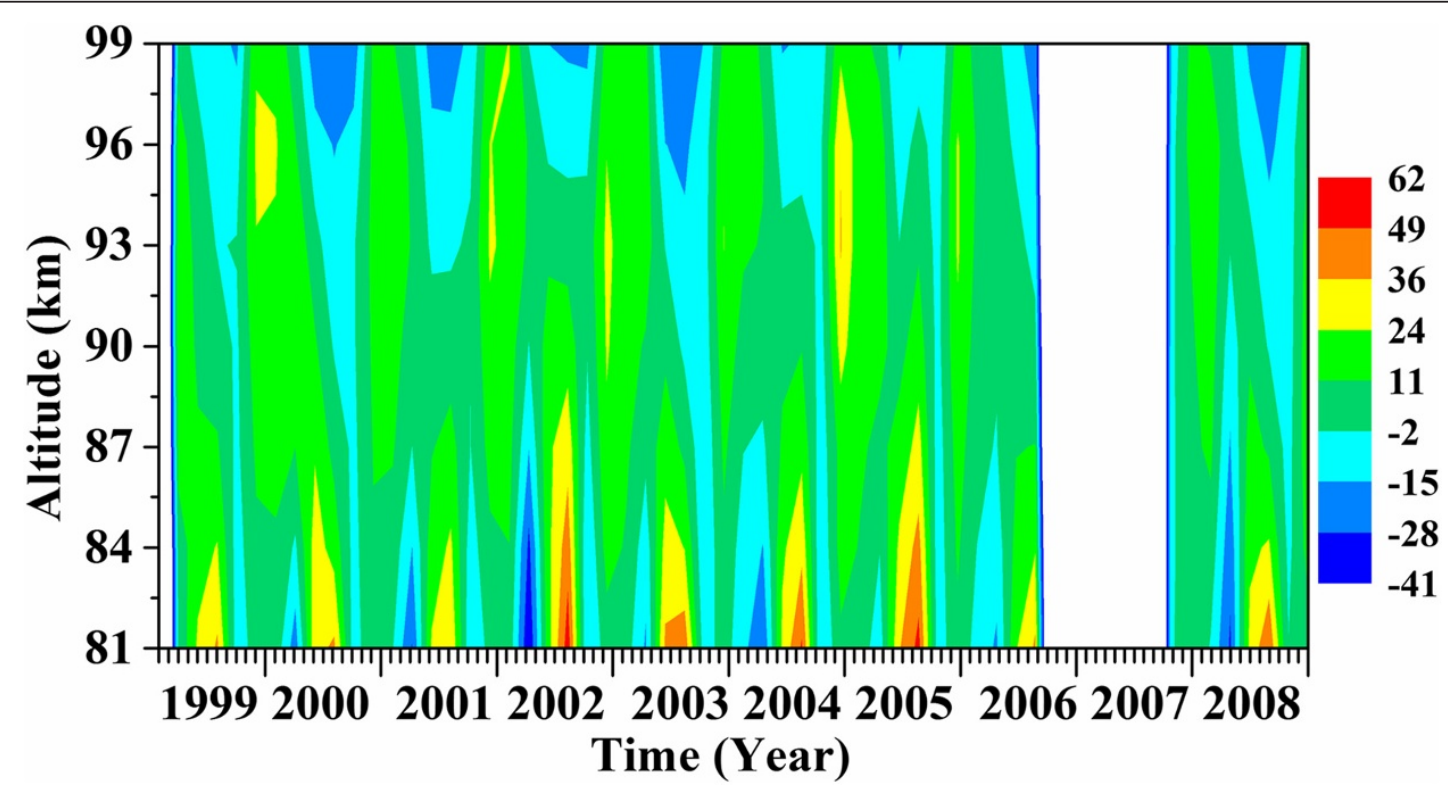

Figure 1 Monthly mean zonal wind in the mesopause during the observational period 1999 to 2008 . 


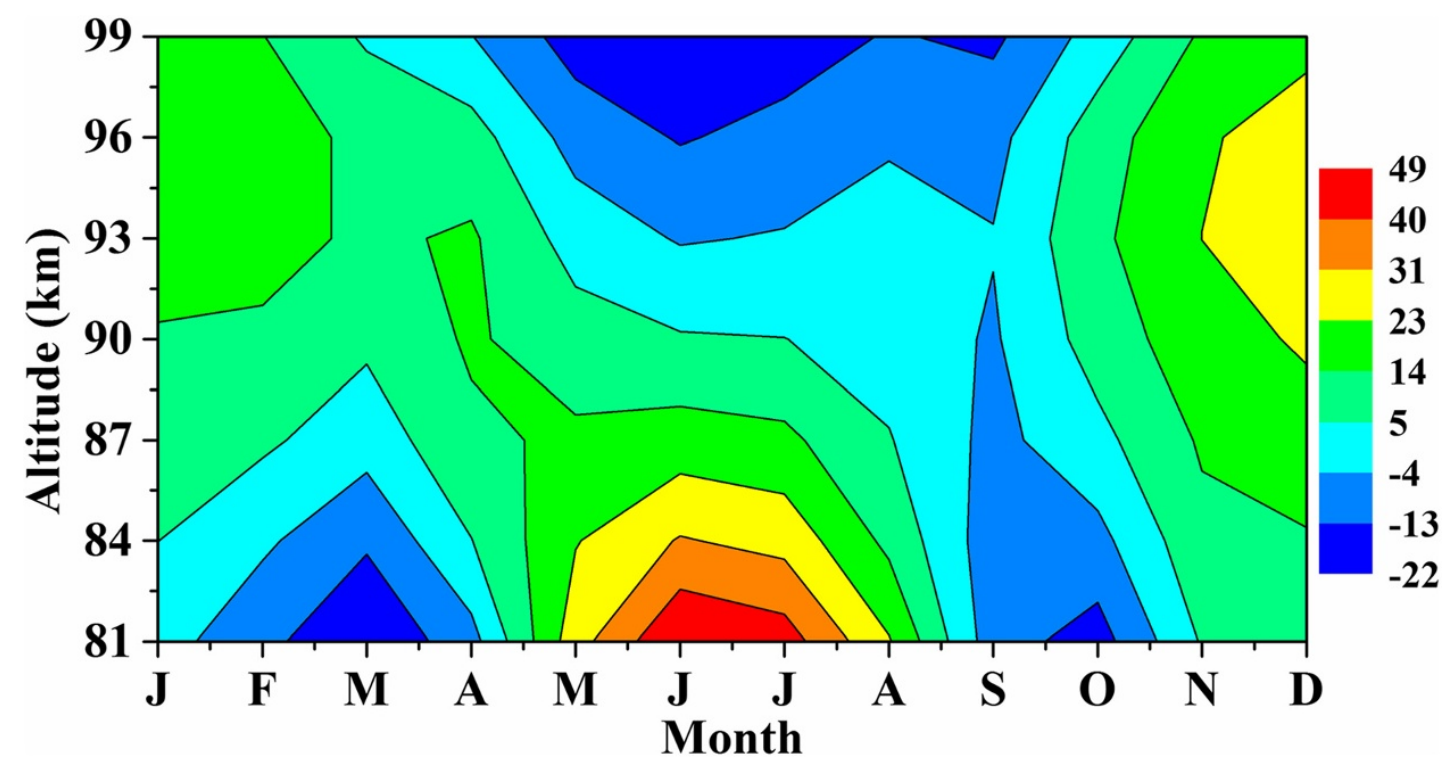

Figure 2 Composite monthly mean zonal wind in the mesopause over whole observational period.

Furthermore, the MSAO (peaks at the solstices and minima at the equinoxes) at lower mesopause indicates a first cycle stronger than the second one implying an asymmetry.

The vertical profiles of the MSAO and MAO amplitude and phase during the observational period are shown in Figure 3a,b,c,d. Horizontal bars in all the subplots denote the associated errors of the estimated parameters. Both MSAO and MAO exhibit highest amplitude ( 22 to $23 \mathrm{~m} / \mathrm{s}$ ) at the lowest altitude. The MSAO amplitude decreases monotonically with altitude up to $90 \mathrm{~km}$ and shows very less variability above that height. The MAO amplitude decreases upward showing a minimum at $87 \mathrm{~km}$ and increases almost monotonically up to $99 \mathrm{~km}$. Therefore, although both MSAO and MAO are evident at lower mesopause levels, the MAO prevails significantly at greater mesopause heights. Both phase profiles show irregular variation with altitude without showing any clear vertical propagation. Since oscillation amplitudes maximize near $81 \mathrm{~km}$, we will consider all comparative analyses at this altitude bin henceforth. For the stratosphere we have selected $10 \mathrm{hPa}$ pressure level representing the mid-stratosphere.

\section{Long-term relationship between $\mathrm{SAO}, \mathrm{AO}$, and $\mathrm{QBO}$}

In the next few sections, we show residual winds after deseasonalizing with some component/s which are abbreviated as follows. The residual wind at a particular altitude bin obtained by removing the climatological mean and AO is referred to as deseasonalized-AO. Similarly, the residual wind derived after removing the climatological mean and SAO is referred to as deseasonalized-SAO. The residual wind estimated by removing the climatological mean, $\mathrm{AO}$, as well as $\mathrm{SAO}$ is referred to as deseasonalized wind.

For comparing mesosphere and stratosphere characteristics, temporal variation of the monthly mean deseasonalized-AO in the zonal wind at $81 \mathrm{~km}$ and deseasonalized-AO in the zonal mean zonal wind at $10 \mathrm{hPa}$ are shown in Figure 4a. Both the winds exhibit a prominent SAO feature with maxima near the solstices. The stratospheric SAO phase leads the mesospheric by a small interval (approximately 1 month) except for 2001 and 2003 winters when both exhibit very similar phases. The SAO amplitude is much higher in the mesosphere as compared to the stratosphere. In the year 2002, the mesospheric SAO shows a trough of maximum amplitude near fall and a crest near winter. Figure $4 \mathrm{~b}$ shows monthly mean deseasonalized-SAO in the zonal wind at $81 \mathrm{~km}$ and deseasonalized-SAO in the zonal mean zonal wind at $10 \mathrm{hPa}$. The plot reveals a prominent $\mathrm{AO}$ of almost the same phase with maxima during winter and minima during summer in the mesosphere and stratosphere. Generally, the mesospheric $\mathrm{AO}$ is stronger than the stratospheric. The stratospheric AO maximum exceeds the mesospheric in 2001 winter and shows very similar amplitude in 2000, 2003, 2006, and 2008 winters. The mesospheric AO shows comparatively large crests during the span in 2002 to 2005 and troughs during 2002, 2004, 2006, and 2008. In Figure 4c we show the monthly mean deseasonalized zonal wind at $81 \mathrm{~km}$ and deseasonalized zonal mean zonal wind at $10 \mathrm{hPa}$. The mesospheric deseasonalized zonal wind reveals dominant crests near late 2002 and mid-2005. Troughs are visible during mid1999, late 2001, and mid-2006. It can be noted that the 


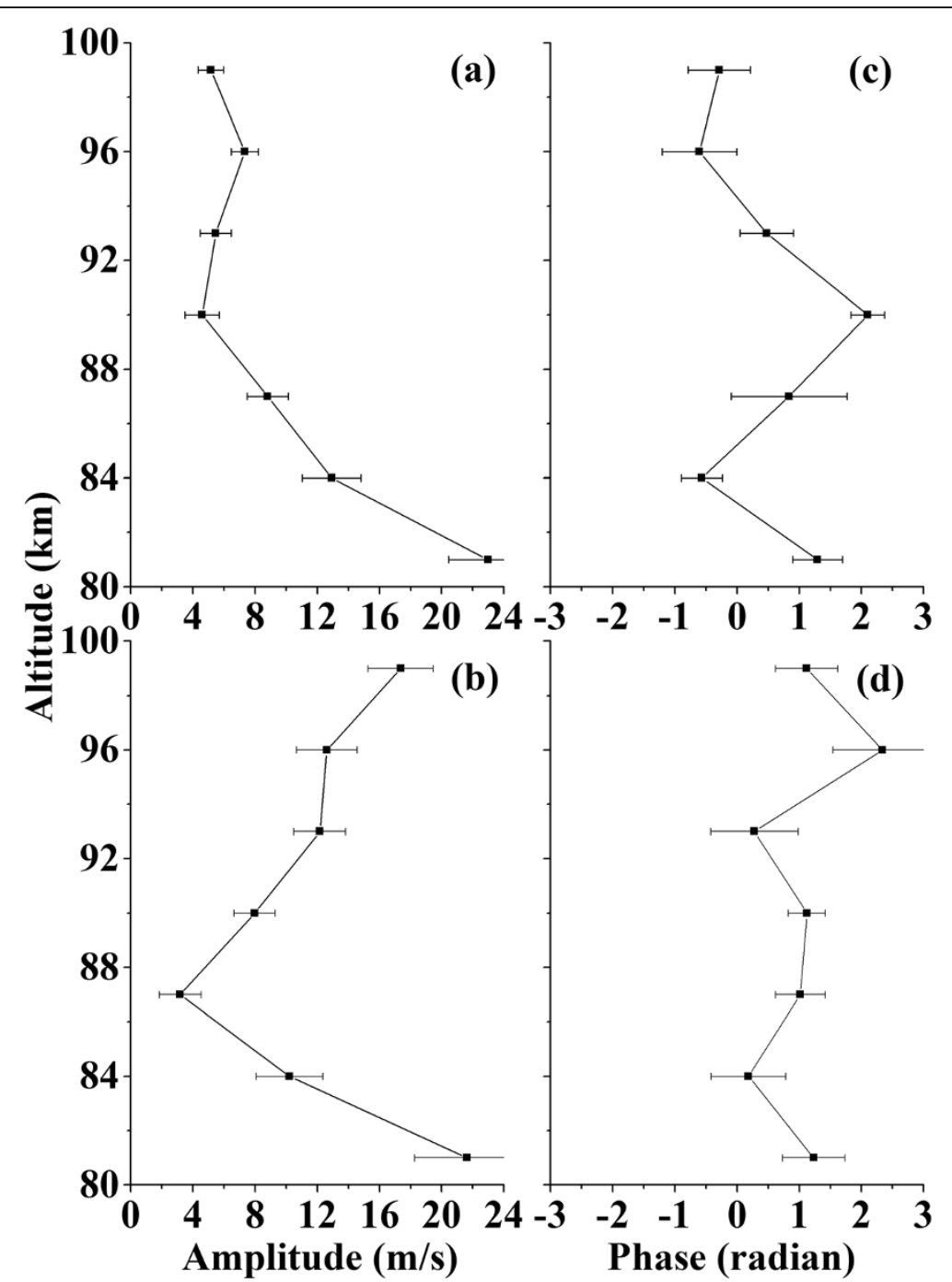

Figure 3 Vertical profiles of the oscillation parameters in the zonal wind in the mesopause. (a) Amplitude of the SAO, (b) amplitude of the $\mathrm{AO}$, (c) phase of the SAO, and (d) phase of the AO.

trough during late 2001 is the strongest of all. Such a distribution of crests and troughs indicates possible existence of a QBO component with a period of 2 to 3 years. Another notable feature is the opposite phase relationship evident in the plot between $\mathrm{MQBO}$ and SQBO during 2001 to 2006. During the 1999 to 2000 time span, the amplitude of the variation is too small to find any relation between stratosphere and mesosphere. In mid-2006 all the oscillations in the stratosphere show the strongest westerly. Similar variation of the deseasonalized wind in the mesosphere and stratosphere is observed in 2008 .

\section{Relationship of the diurnal tide and QTDW with the} above oscillations

To study the relationship of the diurnal tide with the long period oscillations in the mesosphere, we have plotted the monthly mean diurnal tide amplitude as well as deseasonalized-AO (SAO), deseasonalized-SAO (AO), deseasonalized (QBO) winds in Figure 5a,b,c, respectively. Here we considered the meridional wind in calculating diurnal tide amplitude since the tidal amplitude is much higher in the meridional wind than in the zonal wind, while $\mathrm{SAO}, \mathrm{AO}$, and $\mathrm{QBO}$ are derived from the zonal wind as described before. Figure $5 \mathrm{a}$ shows that the higher amplitude of the diurnal tide coincides with easterly phases of the SAO and vice versa most of the times throughout the observational span. In general, the diurnal tide exhibits two peaks in a year during equinoxes with the first peak (fall) larger than the second (spring). It also shows significantly large amplitude during fall equinoxes of 2002, 2004, 2006, and 2008. One can note in Figure 5b that the westerly phase of the $\mathrm{AO}$ coincides with the amplitude minima of the diurnal tide during winter. 


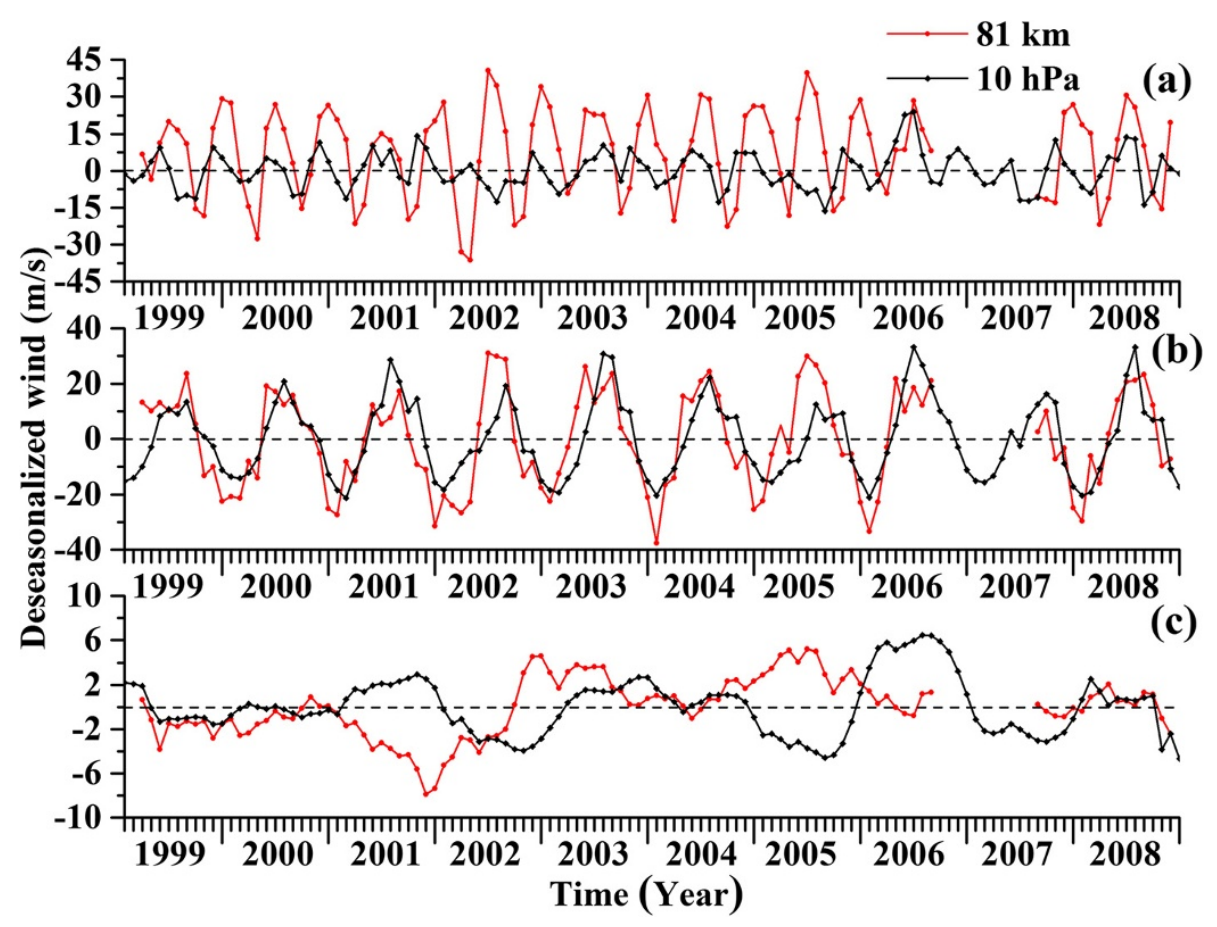

Figure 4 Temporal variation of the monthly mean residual zonal wind. (a) deseasonalized-AO wind at $81 \mathrm{~km}$ and $10 \mathrm{hPa}$, (b) deseasonalized-SAO wind at $81 \mathrm{~km}$ and $10 \mathrm{hPa}$, and (c) deseasonalized wind at $81 \mathrm{~km}$ and $10 \mathrm{hPa}$. The dashed horizontal line denotes zero wind. Please see the text for details of the abbreviations.

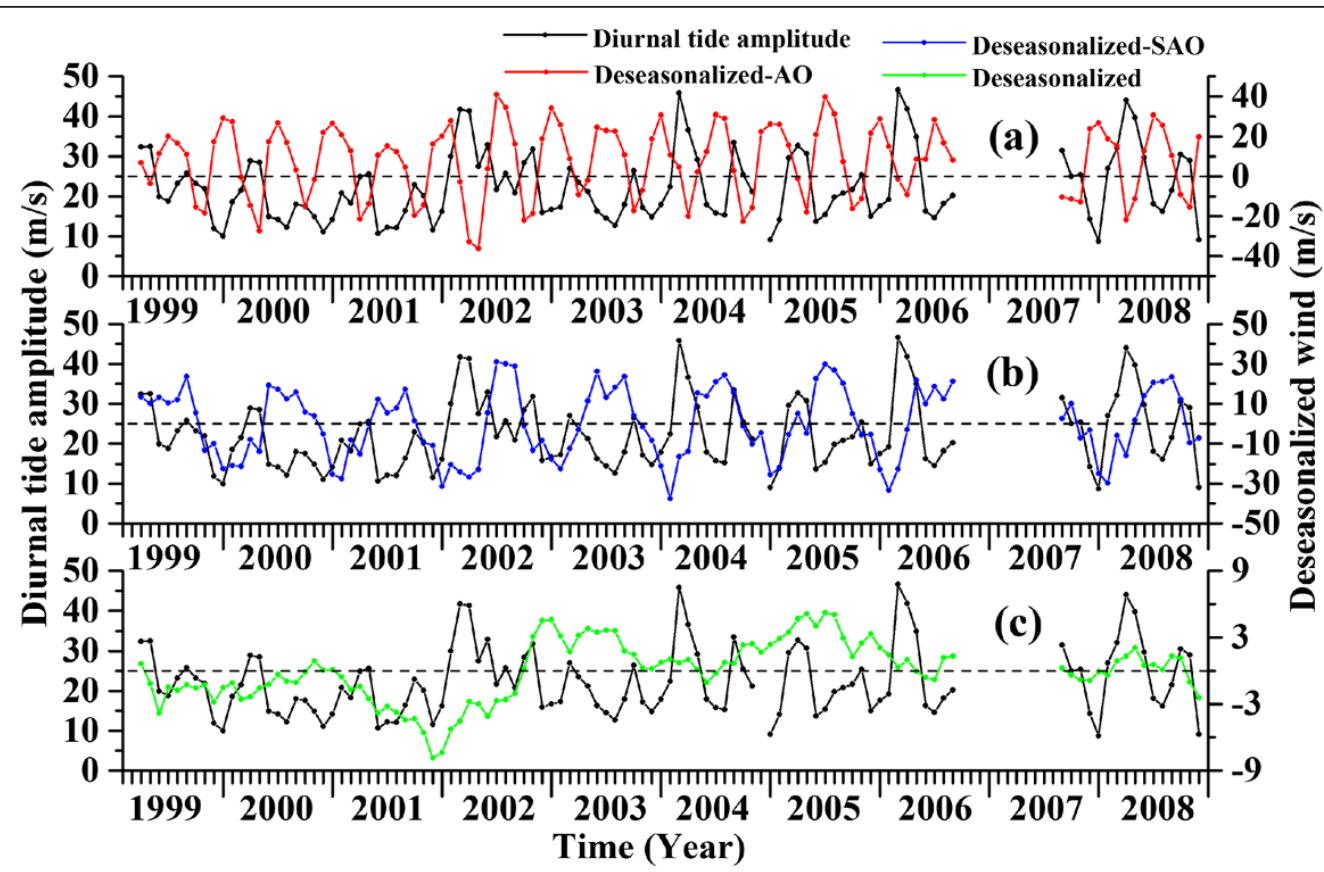

Figure 5 Temporal variation of the monthly mean tidal amplitude and residual zonal wind. (a) diurnal tide amplitude and deseasonalized-AO ( $\sim \mathrm{SAO})$ wind, (b) diurnal tide amplitude and deseasonalized-SAO ( $\sim \mathrm{AO})$ wind, and (c) diurnal tide amplitude and deseasonalized ( QBO) wind. The dashed horizontal line denotes zero wind. Please see the text for details of the abbreviations. 


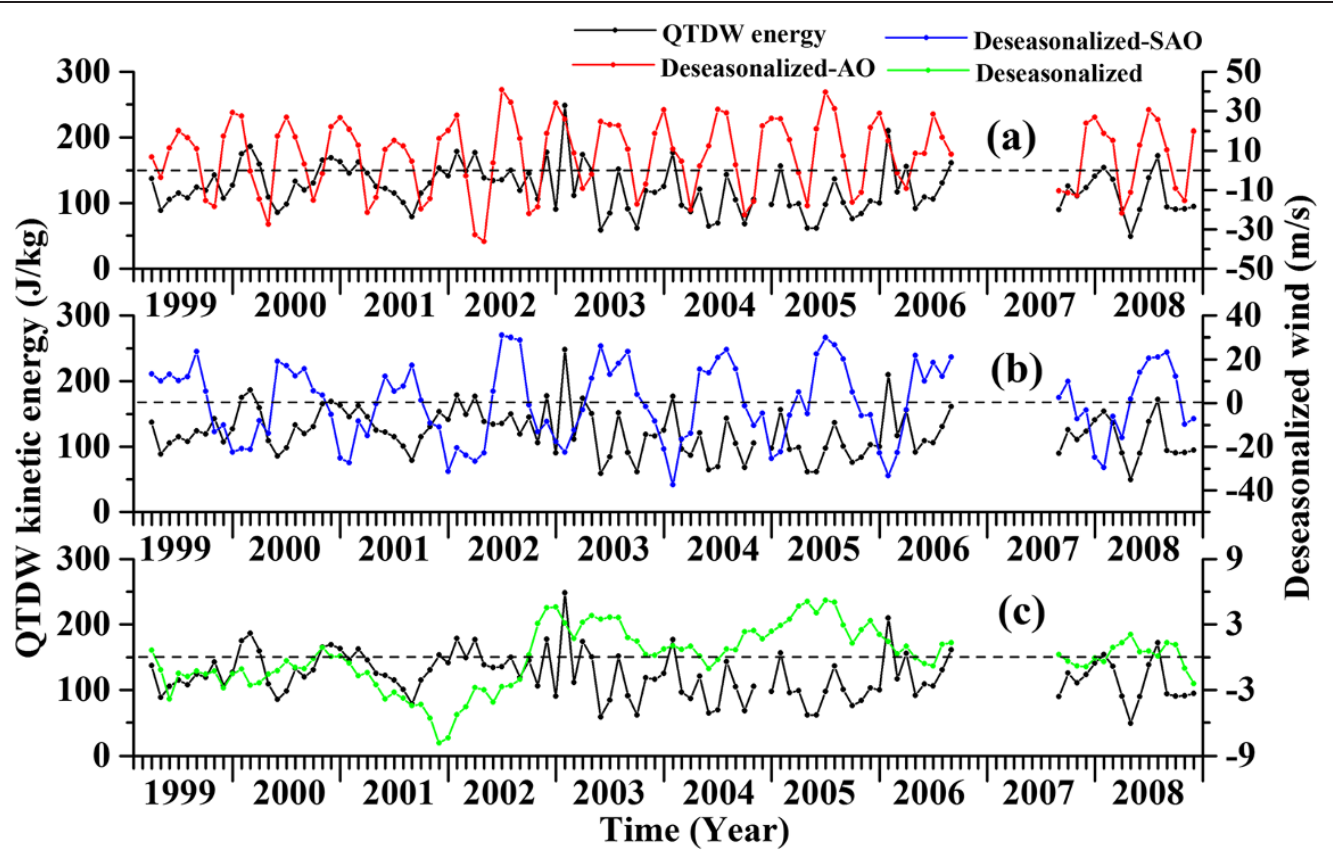

Figure 6 Temporal variation of the monthly mean QTDW kinetic energy and residual zonal wind. (a) QTDW kinetic energy and deseasonalized-AO ( SAO) wind, (b) QTDW kinetic energy and deseasonalized-SAO ( AO) wind, and (c) QTDW kinetic energy and deseasonalized ( QBO) wind. The dashed horizontal line denotes zero wind.

Coincidence of the high diurnal tide amplitude with the easterly phases of the AO is observed in 2002, 2004, 2006, and 2008 fall equinoxes. Variation of the diurnal tide and QBO as shown in Figure 5c shows that remarkably high diurnal tide amplitude occurs close to the easterly peaks of the QBO although a finite time lag exists in 2002, 2004, 2006, and 2008. Also, amplitude peaks (comparatively smaller) in concert with the easterly QBO phase and vice versa are evident in 2000, 2003, and 2005.

The relationship between QTDW and the long period oscillations in the mesosphere is examined in Figure 6a,

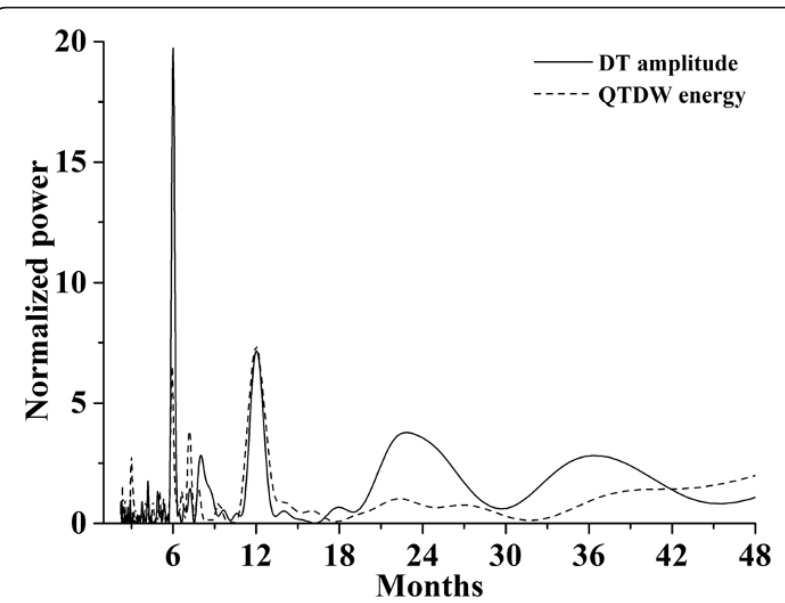

Figure 7 Lomb-Scargle periodogram of the monthly mean diurnal tide amplitude and QTDW kinetic energy at $81 \mathrm{~km}$. b,c in the same way as described in Figure 5 by considering QTDW kinetic energy. In Figure 6a we can note the QTDW kinetic energy maxima coincide with the westerly peaks of the SAO quite often. In a similar fashion, QTDW energy minima concur with the easterly peaks of the SAO most of the time. The maximum QTDW kinetic energy is observed near early 2003. In Figure 6b high QTDW kinetic energy and corresponding easterly AO peak and vice versa is very evident during the intervals in 1999 to mid-2004 and in 2006 to 2007. In Figure 6c we find a concurrence of strong easterly peak of QBO with large QTDW kinetic energy in the late 2001. The highest QTDW kinetic energy peak during early 2003 exhibits a coincidence with the westerly QBO peak.

To further verify the relationship of the diurnal tide and QTDW with these long period oscillations, a Lomb-Scargle periodogram of monthly mean diurnal tide amplitude and QTDW kinetic energy at $81 \mathrm{~km}$ is derived and the normalized power is shown in Figure 7 . The diurnal tide exhibits dominant peaks of the spectral power at periods of 6 (SAO) and 12 months (AO). It also shows minor peaks near the periodicities of 23 and 37 months (QBO). The strongest peak at the period of 6 months indicates significant modulation of the diurnal tide by the SAO in the mesosphere. The QTDW kinetic energy peaks prominently near 6 and 12 months, confirming its relationship with the $\mathrm{SAO}$ and $\mathrm{AO}$, but it does not show any appreciable relation with the $\mathrm{QBO}$ unlike the diurnal tide. 


\section{Discussion}

In the present paper, we show long-term and seasonal behavior of the SAO, $\mathrm{AO}$, and $\mathrm{QBO}$ as well as their interrelationship over a Brazilian low-latitude station. Since studies of these influential oscillations from the southern hemisphere are very rare, our investigation with an adequate database is important in the perspective of present state of knowledge in this field.

The observed asymmetric MSAO peaks in the lower mesopause region, i.e., the higher amplitude during the first cycle than the second cycle in the composite monthly mean zonal wind profile (Figure 2) is similar to the earlier results from the low-latitude middle atmosphere (Garcia et al. 1997; Hirota 1978; Li et al. 2012; Venkateswara Rao et al. 2012; Day and Mitchell 2013).

Seasonal asymmetry of the SSAO structure is explained as larger planetary wave activity in the northern hemisphere winter according to Delisi and Dunkerton (1988), which was later extended to describe MSAO asymmetric behavior by Garcia and Clancy (1990). Burrage et al. (1996) pointed out that a combination of the MSAO with different annual oscillations may also cause asymmetry of the MSAO. They also cautioned that a combination of the MSAO with the MQBO may also cause such asymmetry if the time series is not sampled for long enough. It is important to mention that although the composite profile reveals seasonal asymmetry of the MSAO, the individual profile of each year does not always show such behavior (e.g., Figure 4) indicating such asymmetric behavior to be intermittent.

The mean amplitude of the MSAO over the observation period shows a gradual decrease with altitude, while the MAO amplitude decreases up to $87 \mathrm{~km}$ and subsequently increases, which behavior agrees very well with the past investigations (Batista et al. 2004; Li et al. 2012) using long-term meteor wind observations over low-latitude

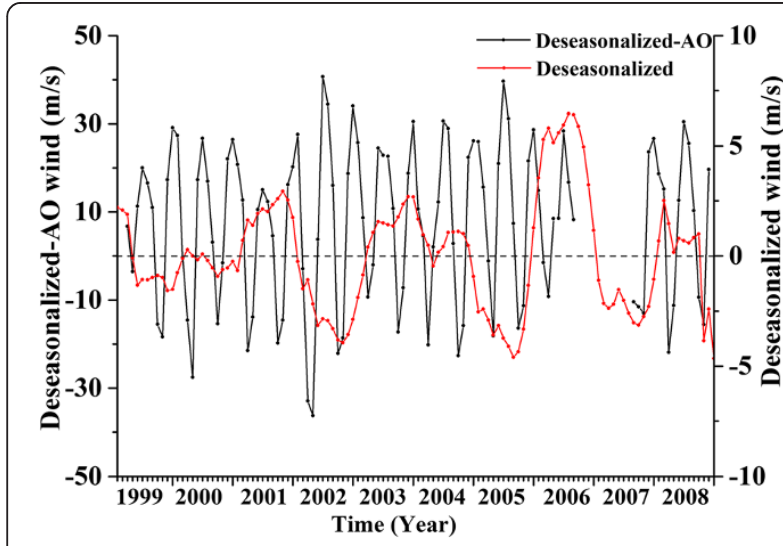

Figure 8 Temporal variation of the monthly mean residual zonal wind. The deseasonalized-AO ( MSAO) wind at $81 \mathrm{~km}$ and deseasonalized ( SQBO) wind at $10 \mathrm{hPa}$ are plotted. The dashed horizontal line denotes zero wind. Please see the text for details of the abbreviations. sites, although our results generally exhibit higher amplitudes $(23 \mathrm{~m} / \mathrm{s}$ for SAO and $21 \mathrm{~m} / \mathrm{s}$ for AO). High MAO amplitude at higher mesopause region is believed to be caused by the existing strong annual winter easterly wind as evident in Figure 1 associated with enhanced dissipation of the westward propagating waves during winter. Considerable interannual variability of the oscillations as seen in the present study is consistent with the past investigations (Sridharan et al. 2007; Venkateswara Rao et al. 2012). The westerly (easterly) winds during solstices (equinoxes) are quite consistent with most of the past studies. However, we find higher magnitude of the westerly wind during solstices as compared to the easterly wind during equinoxes unlike a few past studies which reported opposite behavior (Burrage et al. 1996; Garcia et al. 1997; Buriti et al. 2008; Venkateswara Rao et al. 2012). The amplitude of the QBO is found to be significantly weak $(<6 \mathrm{~m} / \mathrm{s})$ as compared to other two oscillations. Our observed MQBO amplitude is consistent with a number of past studies (Ratnam et al. 2008; Venkateswara Rao et al. 2012; Li et al. 2012; De Wit et al. 2013), although SQBO amplitude is significantly smaller than those studies. The QBO amplitude is higher during 2001 to 2006 in the mesosphere. In the stratosphere the $\mathrm{QBO}$ is not found to be very prominent most of the time except in 2005 to 2006 when it is appreciable. Such intermittent nature of QBO activity was also reported by earlier observations (Ratnam et al. 2008; Venkateswara Rao et al. 2012; De Wit et al. 2013). Overall, mesospheric oscillation amplitudes are higher than the stratospheric.

The MSAO variation in the deseasonalized-AO zonal wind at $81 \mathrm{~km}$ shows almost the same phase relation (approximately 1 month difference) with the SSAO at $10 \mathrm{hPa}$ similar to the finding of Li et al. (2012) based on northern low-latitude observations. The AO obtained from the deseasonalized-SAO zonal wind in the stratosphere and mesosphere shows westerly phase during winter and easterly phase during summer at lower mesopause. Considerably higher amplitude $(>10 \mathrm{~m} / \mathrm{s})$ of the AO signifies its role in determining the preferential zonal direction of wave propagation over various seasons of the year through filtering. We observe an opposite phase relationship of the $\mathrm{QBO}$ in the mesopause and midstratosphere, supporting the results of a number of past investigations (Burrage et al. 1996; Sridharan et al. 2007; $\mathrm{Li}$ et al. 2012). It is believed that the gravity waves are filtered through the SQBO and dissipate in the mesosphere region causing the generation of the equatorial MQBO (Baldwin et al. 2001). Most recently, De Wit et al. (2013) examined the role of selective filtering of the gravity waves by the $\mathrm{SQBO}$ to drive the MQBO using long-term meteor wind data over Ascension Island $\left(8^{\circ} \mathrm{S}, 14^{\circ} \mathrm{W}\right)$. Our observed period of the $\mathrm{QBO}$ is approximately 2 to 3 years. Earlier, Li et al. (2012) found the QBO 
period in the stratosphere and mesosphere of approximately 22 to 24 months. Burrage et al. (1996) obtained the period of the QBO around 2 years in the middle atmosphere. Using MF radar observations over an equatorial station, Sridharan et al. (2007) showed the QBO period of approximately 2 to 3 years. Therefore, the results of the past investigators are quite consistent with the present finding. It is believed that there may be a possible role of the solar cycle in lengthening the period of the SQBO (Mayr et al. 2006).

A number of previous investigators reported modulation of the MSAO by the SQBO. In order to investigate the relationship between the MSAO and SQBO, we have shown the monthly mean deseasonalized-AO $(\sim \mathrm{MSAO})$ zonal winds at $81 \mathrm{~km}$ and deseasonalized ( $\sim \mathrm{SQBO})$ zonal mean zonal wind at $10 \mathrm{hPa}$ level in Figure 8 . It can be noted that the strongest easterly phases of the MSAO as observed in early 2000 , early 2002, late 2004, and early 2008 are accompanied by the westerly (2000, 2004, and 2008) and easterly (2002) phases of the SQBO. Garcia et al. (1997) reported a strong modulation of the easterly MSAO phase by the westerly SQBO phase and weak modulation while the SQBO phase is easterly and they explained this phenomenon by gravity waves filtering by the SQBO with the help of a modeling study which was supported by a number of other studies (Burrage et al. 1996; Baldwin et al. 2001; Ratnam et al. 2008; Day and Mitchell 2013). Our result is partially consistent with the findings of these investigators (during 2000, 2004, and 2008). In contrast to the investigators mentioned before, $\mathrm{Li}$ et al. (2012) found strong easterly MSAO phase at the time of strong easterly SQBO phase and weak easterly MSAO while SQBO phase is westerly. Also Ratnam et al. (2008) reported strong easterly MSAO phase during easterly SQBO phase for a few cases. In fact, such a phenomenon is also found in the present study during certain times, e.g., 2005. Additionally, we find weakest easterly of the MSAO during early 2003 and early 2006 while the SQBO is westerly similar to Li et al. (2012). The maximum easterly amplitude of the MSAO is obtained in 2002 which is also observed by the most recent study of Day and Mitchell (2013) using observations over Ascension Island.

We observe strong westerly phases of the MSAO in 2002 and 2005 with simultaneous easterly phases of the SQBO which is in agreement with the filtering of the eastward propagating gravity waves by the easterly SQBO and dissipation of the same in the mesosphere. A strong westerly phase of the MSAO can also be driven by the eastward propagating ultrafast Kelvin wave which originates in the troposphere and reaches the mesosphere after getting filtered in the stratosphere by the easterly SQBO. Dissipation of the ultrafast Kelvin wave can provide eastward forcing to the mean flow in the mesosphere which may contribute to the westerly phase of the MSAO (Dunkerton 1982).

It is interesting to note that there is an enhancement of all the oscillation components during 2002 in the mesosphere (Figure 4) but not observed in the stratosphere. The enhancement of the easterly phases of all oscillations is followed by the strong westerly phases in 2002. This phenomenon can be attributed to seasonally dependent wave breaking/dissipation with westward propagating dominant waves (Rossby waves, gravity waves, tides) during early 2002 and eastward progressing waves (Kelvin waves, gravity waves) during late 2002. As this phenomenon is not present in the stratosphere, the waves can be deemed as enhanced dissipation in the mesopause probably due to existing instability. Another interesting feature can be pointed out in Figure 4 is the almost periodic enhancement of the easterly phase of the MAO in early 2002, 2004, 2006, and 2008, which indicates a QBO modulation of the MAO. Recently, Ratnam et al. (2008) showed modulation of the MSAO by the MQBO as a result of interaction between these two oscillation components. They explained the relationship between the MSAO and MQBO in terms of their common driving source, i.e., gravity waves which may hold true for the present observed modulation of the MAO by the MQBO also. It should be mentioned that the diurnal tide also shows amplitude maxima (Figure 5) during March/April in the years 2002, 2004, 2006, and 2008, indicating a quasi-biennial modulation. Such quasi-biennial enhancement of the diurnal tide amplitude was also reported in the available literature (Vincent et al. 1998; Wu et al. 2008). Therefore, the diurnal tide as well as gravity waves are supposed to be responsible for such quasi-biennial modulation of the MAO in the present case since these waves are the dominant driver for large scale oscillations in the atmosphere. In this context it can be mentioned that Venkateswara Rao et al. (2012) observed enhancement of the easterly wind during March equinox with a period of approximately 2 years which was termed a quasi-biennial enhancement in their paper. The observed strongest westerly (Figure 4) in all oscillations in mid-2006 in the stratosphere can be attributed to momentum deposition by the eastward propagating gravity waves and Kelvin waves to the background flow.

Earlier, Xu et al. (2009) reported prominent SAO, AO, and $\mathrm{QBO}$ variability of the diurnal amplitude in the tropical mesosphere near $\pm 20^{\circ}$ latitudes using satellitebased observations which is also evident in the present study. The present diurnal tide amplitude shows semiannual variability with maxima during equinoxes (Figure 5 ). The amplitude peak observed during the March/April equinox is significantly higher than the spring maximum, which supports the findings of a number of past investigations (Vincent et al. 1998; Wu et al. 2008; Xu et al. 2009). 
Since the MSAO phase is easterly during equinoxes, it can be made out that the westward propagating diurnal tide plays a vital role in driving the MSAO easterly phase during equinoxes by providing significant momentum to the mean flow. It can also be noted that the quasi-biennial enhancement of the tide amplitude in the mesosphere (as mentioned in the previous paragraph) occurs while the MQBO is easterly (Figure 5c), i.e., the SQBO is in a westerly phase which agrees well with the satellite-based observations over the globe by Wu et al. 2008. The westerly phase of the SQBO allows the westward propagating diurnal tide to pass to the mesosphere through wave filtering. Wu et al. (2008) concluded a possible relationship of weak gravity wave filtering and strong migrating diurnal tide filtering associated to westerly phase of the SQBO. Gurubaran and Rajaram (2001) inferred the possible role of interaction between the gravity waves and diurnal tide to alter the strength of the easterly phase of the MSAO. Unfortunately, in the present study, we are unable to verify the role of gravity waves with the present low temporal resolution wind data. The observed period of the QBO in the diurnal tide amplitude is very near to 23 and 37 months (Figure 7) matching partially with the results of Xu et al. (2009) from low latitudes where they found a period close to 24 to 25 months.

The high QTDW kinetic energy concurs with the westerly phase of the MSAO and vice versa (Figure 6a) indicating a high possibility of westward propagating QTDW filtering by the MSAO. On the contrary, the occurrence of the QTDW energy maxima during the MAO easterly phase (Figure $6 \mathrm{~b}$ ) may suggest that the summer mesospheric easterly jet plays a vital role to enhance the QTDW energy since the summer mesospheric easterly jet facilitates barotropic/baroclinic instability causing QTDW amplification (McCormack et al. 2009; Guharay et al. 2013). The summer mesospheric easterly jet is considered to be generated by dissipation of the westward propagating gravity waves which are filtered by the westerly SQBO. Also high QTDW energy is observed during strong easterly phase of the MQBO in early 2002 (Figure 6c), although it is not found in any other time over the observational span. The large QTDW energy may contribute to strengthen the easterly phase of the mean background wind to some extent. However, the actual role of the gravity waves and QTDW to control the easterly wind can only be ascertained with further intensive analysis which is beyond the scope of the present study. Li et al. (2012) found the QBO enhancement of the easterly wind as well as QTDW energy in the mesosphere and indicated a possible contribution of the QTDW towards driving the easterly phase of the MSAO and MQBO. Our results show SAO and AO modulation in the QTDW energy (Figure 8) although the QBO effect is not prominent suggesting its considerable relationship with $\mathrm{SAO}$ and $\mathrm{AO}$.

\section{Conclusions}

Our study carried out with the meteor radar zonal wind over a low-latitude southern hemispheric station shows the existence of dominant MSAO and MAO in the mesopause region. The MSAO amplitude decreases gradually with altitude while the MAO amplitude is dominant at lower and upper mesopause heights. The long-term pattern shows significant interannual variability. The deseasonalized zonal winds at lower mesopause $(81 \mathrm{~km})$ and mid-stratosphere $(10 \mathrm{hPa})$ show weak QBO oscillations (as compared to the $\mathrm{SAO}$ and $\mathrm{AO}$ ) with opposite phase variation. There is a firm evidence of modulation of the MSAO and MAO by the QBO. The diurnal tide is surmised to be a dominant driver of these oscillations by depositing westward momentum to the mean flow during the easterly phase, although the possibility of modulation of the diurnal tide by these oscillations cannot be ruled out. The relationship of the diurnal tide is believed to be most prominent with the SAO and least with the QBO. The MSAO supports the QTDW activity by filtering. The easterly MAO at lower mesopause possibly favors the growth of the barotropic/baroclinic instability to cause amplification of the QTDW during summer. Significant forcing of the westward propagating QTDW may contribute to the easterly AO phase to some extent.

\section{Competing interests}

The authors declare that they have no competing interests.

\section{Authors' contributions}

AG conceived the ideas and carried out analyses of the work. PPB and BRC participated in the observations of the meteor radar. PPB carried out radar data processing as well as assisted in manuscript preparation. BRC corrected the manuscript. All authors read and approved the final manuscript.

\section{Acknowledgements}

AG sincerely thanks Fundação de Amparo a Pesquisa do Estado de São Paulo (FAPESP) for the financial support. The authors are grateful to ECMWF team for providing the necessary dataset which is available at http://www. ecmwf.int/research/era/do/get/index. The authors also thank the reviewers for their useful comments.

Received: 13 February 2014 Accepted: 14 May 2014

Published: 29 May 2014

\section{References}

Baldwin MP, Gray L, Dunkerton TJ, Hamilton K, Haynes PH, Randel WJ, Holton JR, Alexander MJ, Hirota I, Horinouchi T, Jones DBA, Kinnersley JS, Marquardt K, Sato K, Takahashi M (2001) The quasi-biennial oscillation. Rev Geophys 39:179-229, doi:10.1029/1999RG000073

Batista PP, Clemesha BR, Tokumoto AS, Lima LM (2004) Structure of the mean winds and tides in the meteor region over Cachoeira Paulista, Brazil $\left(22.7^{\circ} \mathrm{S}\right.$ $45^{\circ} \mathrm{W}$ ) and its comparison with models. J Atmos Sol Terr Phys 66:623-636 Buriti RA, Hocking WK, Batista PP, Medeiros AF, Clemesha BR (2008) Observations of equatorial mesospheric winds over Cariri $\left(7.4^{\circ} \mathrm{S}\right)$ by a meteor radar and comparison with existing models. Ann Geophys 26:485-497

Burrage MD, Skinner WR, Gell DA, Hays PB, Marshall AR, Ortland DA, Manson AH, Franke SJ, Fritts DC, Hoffman P, McLandress C, Niciejewski R, Schmidlin FJ, Shepherd GG, Singer W, Tsuda T, Vincent RA (1996) Validation of mesosphere 
and lower thermosphere winds from the high resolution Doppler imager on UARS. J Geophys Res 101(D6):10,365-10,392, doi:10.1029/95JD01700

Day KA, Mitchell NJ (2013) Mean winds in the MLT, the SQBO and MSAO over Ascension Island $\left(8^{\circ} \mathrm{S}, 14^{\circ} \mathrm{W}\right)$. Atmos Chem Phys 13:9515-9523, doi:10.5194/ acp-13-9515-2013

De Wit RJ, Hibbins RE, Espy PJ, Mitchell NJ (2013) Interannual variability of mesopause zonal winds over Ascension Island: coupling to the stratospheric QBO. J Geophys Res Atmos 118(12):12,052-12,060, doi:10.1002/2013JD020203

Delisi DP, Dunkerton T (1988) Seasonal variation of the semiannual oscillation. J Atmos Sci 45:2772-2787, doi:10.1175/1520-0469(1988)045<2772:SVOTSO >2.0.CO;2

Dunkerton TJ (1982) Theory of the mesopause semiannual oscillation. J Atmos Sci 39:2681-2690, doi:10.1175/1520-0469(1982)039<2681:TOTMSO>2.0.CO;2

Garcia RR, Clancy RT (1990) Seasonal variation in equatorial mesosphere temperatures observed by SME. J Atmos Sci 47:1666-1673, doi:10.1175/15200469(1990)047<1666:SVIEMT>2.0.CO;2

Garcia RR, Dunkerton TJ, Lieberman RS, Vincent RA (1997) Climatology of the semiannual oscillation of the tropical middle atmosphere. J Geophys Res 102 (D22):26,019-26,032, doi:10.1029/97JD00207

Guharay A, Nath D, Pant P, Pande B, Russell JM III, Pandey K (2009) Observation of semiannual and annual oscillation in equatorial middle atmospheric long term temperature pattern. Ann Geophys 27:4273-4280, doi:10.5194/angeo-27-42732009

Guharay A, Batista PP, Clemesha BR, Schuch NJ (2013) Study of the quasi-two-day wave during summer over Santa Maria, Brazil using meteor radar observations. J Atmos Sol Terr Phys 92:83-93, doi:10.1016/j.jastp.2012.10.005

Gurubaran S, Rajaram R (2001) Mean winds, tides, and gravity waves during the westward phase of the mesopause semiannual oscillation (MSAO). J Geophys Res 106(D23):31817-31824, doi:10.1029/2001JD000325

Hirota I (1978) Equatorial waves in the upper stratosphere and mesosphere in relation to the semiannual oscillation of the zonal mean wind. J Atmos Sci 35:714-722, doi:10.1175/1520-0469(1978)035<0714:EWITUS>2.0.CO;2

Hocking WK, Fuller B, Vandepeer B (2001) Real-time determination of meteor related parameters utilizing modern digital technology. J Atmos Sol Terr Phys 63:155-169

Holton JR (1983) The influence of gravity wave-breaking on the general circulation of the middle atmosphere. J Atmos Sci 40:2497-2507

Holton JR, Wehrbein WM (1980) The role of forced planetary waves in the annual cycle of the zonal mean circulation of the middle atmosphere. J Atmos Sci 37:1968-1983

Li T, Liu AZ, Lu X, Li Z, Franke SJ, Swenson GR, Dou X (2012) Meteor-radar observed mesospheric semi-annual oscillation (SAO) and quasi-biennial oscillation (QBO) over Maui, Hawaii. J Geophys Res 117:D05130, doi:10.1029/2011JD016123

Mayr HG, Mengel JG, Wolff CL, Porter HS (2006) QBO as potential amplifier of solar cycle influence. Geophys Res Lett 33:L05812, doi:10.1029/2005GL025650

McCormack JP, Coy L, Hoppel KW (2009) Evolution of the quasi 2-day wave during January 2006. J Geophys Res 114:D20115, doi:10.1029/2009JD012239

Ratnam MV, Kumar GK, Murthy BVK, Patra AK, Rao WMJ, Rao SVB, Kumar KK, Ramkumar G (2008) Long-term variability of the low latitude mesospheric $\mathrm{SAO}$ and $\mathrm{QBO}$ and their relation with stratospheric QBO. Geophys Res Lett 35:L21809, doi:10.1029/2008GL035390

Reed RJ (1966) Zonal wind behavior in the equatorial stratosphere and lower mesosphere. J Geophys Res 71:4223-4233

Sassi F, Garcia RR (1994) A one-dimensional model of the semiannual oscillation driven by convectively forced gravity waves.J Atmos Sci 51:3167-3182

Sato K, Dunkerton TJ (1997) Estimates of momentum flux associated with equatorial Kelvin and gravity waves. J Geophys Res 102(24):261-26,247

Sridharan S, Tsuda T, Gurubaran S (2007) Radar observations of long-term variability of mesosphere and lower thermosphere winds over Tirunelveli $\left(8.7^{\circ} \mathrm{N}, 77.8^{\circ} \mathrm{E}\right)$. J Geophys Res 112:D23105

Venkateswara Rao N, Tsuda T, Riggin DM, Gurubaran S, Reid IM, Vincent RA (2012) Long-term variability of mean winds in the mesosphere and lower thermosphere at low latitudes. J Geophys Res 117:A10312, doi:10.1029/ 2012JA017850

Vincent RA, Kovalam S, Fritts DC, Isler JR (1998) Long-term MF radar observations of solar tides in the low-latitude mesosphere: interannual variability and comparisons with the GSWM. J Geophys Res 103:8667-8683, doi:10.1029/98JD00482

Wu Q, Ortland DA, Killeen TL, Roble RG, Hagan ME, Liu HL, Solomon SC, Xu J, Skinner WR, Niciejewski RJ (2008) Global distribution and interannual variations of mesospheric and lower thermospheric neutral wind diurnal tide: 1. Migrating tide. J Geophys Res 113:A05308, doi:10.1029/2007JA012542

Xu J, Smith AK, Liu H-L, Yuan W, Wu Q, Jiang G, Mlynczak MG, Russell JM III, Franke SJ (2009) Seasonal and quasi-biennial variations in the migrating diurnal tide observed by Thermosphere, Ionosphere, Mesosphere, Energetics and Dynamics (TIMED). J Geophys Res 114:D13107, doi:10.1029/2008JD011298

\section{doi:10.1186/1880-5981-66-45}

Cite this article as: Guharay et al:: On the variability of the seasonal scale oscillations over Cachoeira Paulista $\left(22.7^{\circ} \mathrm{S}, 45^{\circ} \mathrm{W}\right)$, Brazil. Earth, Planets and Space 2014 66:45.

\section{Submit your manuscript to a SpringerOpen ${ }^{\circ}$ journal and benefit from:}

- Convenient online submission

- Rigorous peer review

- Immediate publication on acceptance

- Open access: articles freely available online

- High visibility within the field

- Retaining the copyright to your article

Submit your next manuscript at $>$ springeropen.com 